\title{
Expressivism about Knowledge and the Value of Knowledge
}

Kappel, Klemens

Published in:

Acta Analytica

DOI:

10.1007/s12136-009-0073-1

Publication date:

2010

Document version

Early version, also known as pre-print

Citation for published version (APA):

Kappel, K. (2010). Expressivism about Knowledge and the Value of Knowledge. Acta Analytica, 25(2), $175-194$. https://doi.org/10.1007/s12136-009-0073-1 


\title{
Expressivism about Knowledge and the Value of Knowledge
}

\author{
Klemens Kappel \\ Philosophy, University of Copenhagen
}

\begin{abstract}
The aim of the paper is to state a version of epistemic expressivism regarding knowledge, and to suggest how this expressivism about knowledge explains the value of knowledge. The paper considers how an account of the value of knowledge based on expressivism about knowledge responds to the Meno Problem, the Swamping Problem, and a variety of other questions that pertains to the value of knowledge, and the role of knowlegde in our cognitive ecology.
\end{abstract}

Key words: value of knowledge, epistemic expressivism, The Meno Problem, The Swamping problem, the value problem, inquiry

\section{Introduction}

Recently, epistemology has focused on the question why knowledge is more valuable than mere true belief, or mere justified true belief? This question is rightly considered important for theories of knowledge, and for providing a philosophical understanding of our cognitive life in general. Any plausible theory of knowledge must be compatible with a plausible story about why we consider knowledge valuable.

Current discussions on the value of knowledge feature a number of different accounts. A widely discussed strategy holds that knowledge arises from the successful exercise of the epistemic virtues, and that the value of 
knowledge should be accounted for in terms of valuable features of the employing epistemic virtues. ${ }^{1}$ Williamson, in his book, suggests that the value of knowledge is to be accounted for in terms of the greater stability of known beliefs compared to mere true belief. ${ }^{2}$ Recently, Goldman and Olsson have proposed two distinct instrumentalist accounts of the value of knowledge. Others have taken a skeptical line. ${ }^{3}$ Kvanvig is a prominent contributor to this debate, and argues that there is no plausible account of the value of knowledge, and consequently he proposes that understanding, rather than knowledge, is valuable. $^{4}$

However, one approach that remains largely unexplored is the expressivist approach. Epistemic expressivism is a general view that applies expressivism to epistemological notions in so far as they have a normative component. What I will refer to as expressivism about knowledge holds, roughly, that to say that $\mathrm{S}$ 's belief that $\mathrm{p}$ is known is to express a particular kind of approval of S's belief that $\mathrm{p}$ and of the epistemic position in which S holds the belief that $\mathrm{p}$. The aim of this paper is to argue that expressivism about knowledge supports an attractive view about the value of knowledge. Among other features, an expressivist account of the value of knowledge is consistent with a range of considered intuitions about the value of knowledge, and it supports an intuitively compelling account of the role of knowledge and

1 See the work by Duncan Pritchard, Ernest Sosa, Linda Zagzebski and others.

2 See Timothy Williamson, Knowledge and Its Limits (Oxford ; New York: Oxford University Press, 2000).

3 See Alvin I. Goldman and E. J Olsson, "Reliabilism and the Value of Knowledge," in Epistemic Value, ed. Duncan Pritchard (Oxford University Press, 2009).

$4 \quad$ See Jonathan L. Kvanvig, The Value of Knowledge and the Pursuit of Understanding, Cambridge Studies in Philosophy (Cambridge, UK ; New York: Cambridge University Press, 2003). 
attributions of knowledge, and the relation these have to the aims of inquiry. In part for these reasons, I think that the account of the value of knowledge that I offer has important advantages over competing accounts of the value of knowledge, though arguing this requires another paper. ${ }^{5}$

Though I obviously think that there is something to be said in favour of that view, the aim of the paper is not to offer a full defence of epistemic expressivism, or even to endorse that view. The aim is the much more modest of detailing what expressivism about knowledge could say about the value of knowledge. A defense of expressivism about knowledge would require at least motivating expressivism about this part of epistemic discourse, and replying to the Frege-Geach objection to expressivist discourse. Moreover, Terence Cuneo and Michael Lynch have recently argued that epistemic expressivism face serious difficulties that are specific to the epistemic domain. ${ }^{6}$ Their claim is that because of the very content of the doctrine, epistemic expressivism cannot be coherently asserted or argued for. Jonathan Kvanvig has pressed a similar argument some years ago in a chapter devoted to a discussion of epistemic expressivism and the value of knowledge. ${ }^{7} \mathrm{I}$ do not think that these latter objections are decisive, but for the purposes of the present paper, I will simply set aside this discussion and focus solely on the capacity of epistemic expressivism to account for the value of knowledge. ${ }^{8}$

$5 \quad$ See my 'Getting the Meno Problem Right' (forthcoming)

6 See Terence Cuneo, The Normative Web : An Argument for Moral Realism (Oxford: Oxford University Press, 2007), Michael Lynch, "Truth, Value and Epistemic Expressivism," Philosophy and Phenomenological Research LXXIX, no. No 1 (2009).

7 See Kvanvig, The Value of Knowledge and the Pursuit of Understanding, 158.

8 See my 'Is Epistemic Expressivism Dialectially Incoherent?' (forthcoming) for a rejection of the arguments proposed by Cuneo, Lynch and Kvanvig. 
A brief overview of the paper may be useful. I section 2 I present my favoured form of expressivism about knowledge, and distinguish this view from a couple of related views. In section 3 I suggest how expressivism about knowledge may account for the value of knowledge. This is applied to The Meno Problem and the Swamping Objection in section 4. Section 5 is devoted to a discussion of certain questions that may be raised to the account. Finally, section 6 offers a few concluding remarks.

\section{Expressivism about Knowledge}

Some remarks about expressivism about knowledge are in order. Epistemic expressivism is not a widely discussed view, and neither are accounts of the value of knowledge based on expressivism. This is striking of course, given that the main question is that of accounting for a normative domain, and that expressivist accounts of normativity and value in the domain of ethics are feature so prominently in the discussion. Expressivism about epistemic discourse is the obvious extension of the forms of expressivism about moral discourse defended by Stevenson and Ayer, and more recently and with great sophistication, by Allan Gibbard and Simon Blackburn. Gibbard and Blackburn have made suggestions as to how their views apply to parts epistemic discourse, and some others have proposed at least similar views. ${ }^{9}$

9 See Simon Blackburn, "Securing the Nots: Moral Epistemology for the Quasi-Realist," in Moral Knowledge. New Readings in Moral Epistemology, ed. Walter Sinnott-Armstrong and Mark Timmons (Oxford University Press, 1996) where Blackburn considers moral epistemology. Gibbard suggests an account of attributions of knowledge in his Allan Gibbard, Thinking How to Live (Cambridge, Mass.; London: Harvard University Press, 2003), chapter 11. Recent work in which epistemic expressivism is discussed (though not always endorsed) is: Kvanvig, The Value of Knowledge and the Pursuit of Understanding, chapter 7; Matthew Chrisman, "From Epistemic Contextualism to Epistemic Expressivism," Philosophical Studies 135 (2007); Cuneo, The 
Hartry Field is an important early proponent of a form of epistemic expressivism, and he has recently restated his views very forcefully. ${ }^{10}$ As Field notes, debates in epistemology are often conducted under the assumption that epistemic evaluations are a kind of factual judgements that assess how much of 'the justificatory fluid' is present in a particular situation or type of situations. ${ }^{11}$ On the view that Field develops, epistemic evaluations are a species of nonfactual evaluations. There are fascinating and important details to Field's view, though this is not the place to discuss them.

For the purposes of the present discussion, however, the important thing to note is that Field's view basically concerns our assessment of belief forming methods. Thus, Field addresses attributions of knowledge only indirectly, and only subject to the further assumption that the evaluative part involved in attributions of knowledge is a function of the evaluative parts of attributions of justification.

The significance of this for the present discussion is the following: the evaluation involved in saying that a belief is known seems to be rather different from that involved in saying that this belief is justifiably believed, and even the belief in question is true and justifiably believed. ${ }^{12}$ For example, saying that a belief is known normally involves judging that further inquiry makes no sense,

Normative Web : An Argument for Moral Realism; H. Field, "Epistemological Nonfactualism and the a Prioricity of Logic," Philosophical Studies 92, no. 1-2 (1998); Lynch, "Truth, Value and Epistemic Expressivism."; H. Field, "Epistemology without Metaphysics," Philosophical Studies 143 (2009). See also Matthew Chrisman, "From Epistemic Expressivism to Epistemic Inferentialism," in Social Epistemology, ed. Adrian Haddock, Duncan Pritchard, and Alan Millar (Oxford University Press, 2009 (forthcoming)).

10 See Field, "Epistemology without Metaphysics."

11 Cf. Ibid.: 249-50.

12 Kvanvig makes a similar note, Kvanvig, The Value of Knowledge and the Pursuit of Understanding, 176. 
and that one should disregard the possibility that the belief be false (or so I claim at least - see the discussion below). Nothing similar seems to be the case with attributions of justification. Saying that Adrian is justified in holding the belief that $\mathrm{p}$ is compatible with holding the evaluative stance that Adrian ought to continue his inquiry whether $\mathrm{p}$ is true. This is so even if, when evaluating Adrian's epistemic situation, one knows $\mathrm{p}$ to be true. So, the pro-attitude involved in saying that a belief is known differs in this respect from the proattitude involved in saying that a belief is justified, and a theory of what it is to attribute knowledge ought to reflect this. The kind of expressivism about knowledge that I set forth below allows for attributions of knowledge and attributions of justification to express distinct kinds of evaluations.

In a recent paper Matthew Chrisman develops a strategy similar to Field's. ${ }^{13}$ Chrisman's main suggestion is that sentences of the form ' $\mathrm{S}$ knows that p' 'could be understood as expressing our acceptance of particular epistemic norms, which when applied to a particular person's belief entitle or don't entitle the belief.' 14 Thus, we can say that sentences of the form 'S knows that p' express a factual content that can be rendered as

(2') $\mathrm{S}$ is entitled by norms $e$ to her true belief that $\mathrm{p}$

The non-factual part of a knowledge claim, then, is the expression of acceptance of certain epistemic norms denoted by ' $e$ '. While there is surely much to be said in favour of the view Chrisman proposed, the view has inherited the problem identified in Field's account. Chrisman's account doesn't clearly distinguish between accepting a true belief with some justification, and

13 Cf. Chrisman, "From Epistemic Contextualism to Epistemic Expressivism," 242ff.. Chrisman has since refined his views on these matters. See his interesting "From Epistemic Expressivism to Epistemic Inferentialism." 14 Cf. Chrisman, "From Epistemic Contextualism to Epistemic Expressivism," 241. 
knowing that belief. Yet, again these epistemic evaluations do seem very different. Saying that $\mathrm{S}$ is to some degree justified in accepting the true belief that $\mathrm{p}$, leaves open whether $\mathrm{S}$ is entitled, or even required, to stop further inquiry, or entitled or required to disregard the possibility that $\mathrm{p}$ is false in her practical deliberation, while saying that $\mathrm{S}$ knows that $\mathrm{p}$ does not leave this open.

As mentioned, Field and Chrisman both seem to assume that the evaluative parts of attributions of knowledge derive from the evaluations of beliefs' justificatory status. I want to propose that attributions of knowledge serve to express a kind of epistemic evaluation that is distinct for knowledge attributions. I shall refer to this view as expressivism about knowledge. The main idea in expressivism about knowledge is to view attributions of knowledge as a kind of evaluation that applies to a subject in a certain epistemic position and a true proposition. Thus, to say that a belief is known (rather than, say, believed truly and with some justification) involves evaluating a subject's epistemic position with respect to a true proposition. Saying that $\mathrm{S}$ knows that $\mathrm{p}$ involves judging that $\mathrm{S}$ 's epistemic position vis-a-vis $\mathrm{p}$ is, in a sense to be specified, good enough. Expressivism about knowledge holds that evaluation involves in attributions of knowledge is an expression of a proattitude. And the kind of pro-attitude involved in knowledge attributions is distinct from other pro-attitudes that we express in other kinds of epistemic evaluations,

Here is what might be a helpful way of fleshing out the view. Consider what I, for lack of a better name, will refer to as the k-norms. When applied to $\mathrm{S}$ 's belief in a proposition $\mathrm{p}$, the k-norms roughly says that $\mathrm{S}$ should regard $\mathrm{p}$ as true, that $\mathrm{S}$ should exempt $\mathrm{p}$ from doubt, that $\mathrm{S}$ shouldn't subject $\mathrm{p}$ to further inquiry (e.g. attempts to undermine or defeat $\mathrm{p}$, or attempts to adduce additional evidence for $\mathrm{p}$ ). Moreover, $\mathrm{S}$ should let $\mathrm{p}$ inform action in such a way that the possibility that $\mathrm{p}$ is false is disregarded. S should, for example, not be willing to bet on the possibility that $\mathrm{p}$ is false.

One could, of course, wish for a much more precise specification of the k-norms, but it is not my aim to provide this here, and the discussion below can 
easily proceed without it. The point of the k-norms, of course, is to specify a role that known beliefs (or beliefs regarded as known) play in our cognitive and practical life. One may debate the details of the k-norms, of course, but it seems fairly uncontroversial that knowledge occupies a rather distinct role in our cognitive and practical life. The role of knowledge is rather different from, say, that of beliefs that are justified but not known. My suggestion is simply that the evaluative expressive content of knowledge attributions should be understood in terms of the k-norms, whatever their exact content. Thus, basically, when we utter tokens of ' $\mathrm{S}$ knows that $\mathrm{p}$ ' about a subject $\mathrm{S}$ holding a true belief that $\mathrm{p}$, we endorse the k-norms with respect to $\mathrm{S}$ and $\mathrm{S}$ 's belief that $\mathrm{p} .{ }^{15}$

Before turning to the question of the value of knowledge, I want to make some further comments about expressivism about knowledge.

Of course, when saying ' $S$ knows that $p$ ' we imply that $S$ is in a sufficiently strong epistemic position with respect to $\mathrm{p}$. To capture this further element let us introduce a notion of an epistemic position. Roughly, S's epistemic position with respect to $\mathrm{p}$ is the set of possible worlds in which $\mathrm{S}$ gets it right with respect to $\mathrm{p} .{ }^{16}$ This is a very rough definition indeed, and it could be replaced by more refined notions, or by notions that are roughly internalist in

15 In response to this, one might suggest a fuller reading of 'entitlement' in Chrisman's (2's) above. The suggestion might go that to be entitled to a true belief that $\mathrm{p}$ by some epistemic norm is to have a permission (or obligation) to regard $\mathrm{p}$ as true, and to suspend further inquiry, and so on. I have no objections to this. The suggestion might simply that the content of being entitled by an epistemic norm to a proposition is provided by the k-norms. With this explication, Chrisman's epistemic expressivism might be identical with the view defended here. Chrisman made this comment in personal communication. 16 Cf. M. Heller, "The Proper Role for Contextualism in an Anti-Luck Epistemology," Nous (1999). To keep the presentation manageable, I have defined epistemic position in terms of possible worlds. This isn't essential, however, and many other ways of understanding epistemic position would do. 
spirit rather than externalist, but for purposes at hand this characterisation will do. The important point is that, as the notion of an epistemic position is defined, to say that $\mathrm{S}$ is in a particular epistemic position is not yet to evaluate that position, or any belief of $\mathrm{S}$ as held in that position. In particular, to say that $\mathrm{S}$ is in certain epistemic position $\mathrm{E}$ with respect to $\mathrm{p}$ is not yet to say that $\mathrm{S}$ knows that $\mathrm{p}$, even if $\mathrm{E}$ is in fact a very strong epistemic position with respect to $\mathrm{p}$. However, not all epistemic positions are equally good. We therefore need ways to evaluate epistemic positions. Expressivism about knowledge may be rendered as the view that knowledge attributions express a specific kind of evaluation of epistemic positions. So when A attributes knowledge to $\mathrm{S}$, this involves an evaluation of S's epistemic position, although perhaps not in the sense that A explicitly refers to any particular epistemic position. At a minimum, however, when attributing knowledge to $\mathrm{S}$, A commits herself to the thought that there is some epistemic position that $\mathrm{S}$ is in and that this position is good enough to deserve the particular kind of approval expressed by A's attribution of knowledge.

The bulk of the epistemological tradition has assumed descriptivism about epistemic discourse, i.e. that tokens of ' $\mathrm{S}$ knows that $\mathrm{p}$ ' and similar locutions are largely descriptive rather than non-descriptive. Moreover, the standard assumption has been that there is some distinct type of fact or type of epistemic state to be captured by correct attributions of knowledge. Let this view be factualism about knowledge. Expressivism about knowledge deny not only descriptivism about this part of epistemic discourse, but also factualism about knowledge. Thus, expressivism about knowledge claim that saying that $\mathrm{S}$ knows that $\mathrm{p}$ does not add anything factual to merely indicating that $\mathrm{S}$ holds a true belief in a epistemic position which one deems good enough. And expressivism about knowledge insists that there is no specific type of epistemic state that could be accurately described by true tokens of ' $\mathrm{S}$ knows that $\mathrm{p}$ '.

As is familiar from the corresponding debates in meta-ethics, one may devise notions of minimal factual content, such that tokens of 'S knows that $\mathrm{p}$ ' express factual content or propositions, even though there is no robust 'external' 
epistemic fact for felicitous utterances of such sentences to track. For the discussions lying ahead, however, we need not go into these further questions.

Of course, for all expressivism about knowledge says, there might be highly relevant facts about the truth of propositions we affirm, about the reliability of various modes of reasoning or belief forming methods or about the truth of various principles we rely upon in our reasoning. There might also be facts about modal properties of believers and the beliefs they hold in various circumstances, or facts about probabilistic relations between beliefs or between beliefs and perceptual states or evidence of other kinds. Let us refer loosely to such facts as epistemically relevant facts.

Expressivism about knowledge holds that attributions of knowledge do not merely report epistemically relevant facts. In addition, attributions of knowledge issue certain forms of evaluations of epistemically relevant facts, or of agents and their states of belief. Thus, though attributions of knowledge are themselves partly non-factual, they nonetheless depend on epistemically relevant facts such as those mentioned.

Here is an overly crude example to illustrate the point. Suppose that $\mathrm{S}$ at $t_{1}$ has acquired her true belief that $p$ by some method $M$ used in circumstances $\mathrm{c}_{1}$ and that $\mathrm{M}$ is very reliable, say $85 \%$, when used by $\mathrm{S}$ in a certain class of circumstances C. Suppose that $\mathrm{S}$ harbours a range of higher order beliefs regarding the propriety of relying on $\mathrm{M}$ for the purposes at hand, and suppose that circumstances $c_{1}$ are included in C. On the basis of this A attributes knowledge to S. Now, expressivism about knowledge holds that A's attribution of knowledge does not merely report the facts mentioned, that is, that $\mathrm{S}$ holds at true belief acquired by $\mathrm{M}$, and that $\mathrm{M}$ is $85 \%$ reliable when used under circumstances $\mathrm{C}$, and that $\mathrm{S}$ 's actual circumstances $\mathrm{c}_{1}$ are included in C. Neither does A's attribution of knowledge report a further epistemic fact about S, say the alleged further epistemic fact that $\mathrm{S}$ knows that $\mathrm{p}$. Rather, A's attribution of knowledge is an appraisal which serves to express a distinct kind of evaluation of S's belief that $p$ as held in S's epistemic position. 
Clearly, there are many kinds of epistemic evaluations, and it is implausible to hold that any of them are mere indiscriminate pro-attitudes. Moreover, some evaluations of belief states are not epistemic in nature and these also need to be differentiated from the evaluations characteristic of knowledge. Hence, we obviously need to ask what characterises the distinctive kind of approval involved in knowledge attributions.

For expressivism about knowledge, the answer to this question is straightforward, and may be put as follows: 'S knows that p' as uttered by A expresses k-approval of S's epistemic position $\mathrm{E}$ with respect to $\mathrm{p}$. To kapprove of S's epistemic position $\mathrm{E}$ with respect to $\mathrm{p}$ just is to endorse the knorms with respect to $\mathrm{S}$ 's belief that $\mathrm{p}$ as held in epistemic position $\mathrm{E}$. Thus, the specific kind of approval or evaluation involved in attributions of knowledge is characterised by the k-norms.

Contrast this with the evaluations involved in attributions of justified belief. Saying that some subject is justified in holding her belief is justified but not known is also endorsing a set of norms, or that the belief in question be treated in accordance with a specific set of norms, but it is a different set of norms. When saying that S's belief that $\mathrm{p}$ is justified one endorses norms regarding S's belief that $\mathrm{p}$ such as: $\mathrm{S}$ may reasonably take $\mathrm{p}$ to be proper ground for action, though depending on circumstances $\mathrm{S}$ should consider the possibility that $\mathrm{p}$ is false, and $\mathrm{S}$ should be open to the possibility that more inquiry is needed. These $j$-norms, as we may call them, are clearly different in content from the k-norms. And assuming that the nature of epistemic evaluations are determined by the norms endorsed in those evaluations, we get that evaluations involved in attributions of knowledge are entirely different from evaluations involved in attributions of justified belief. ${ }^{17}$

17 Compare Ibid.: 119 where Heller remarks: "'Knowledge" is our word for saying that S's epistemic condition is good enough when she has a true belief without saying exactly what that condition is'. I agree, but Heller's view 
In his book, Kvanvig voiced the worry that the positive endorsements involved in attributions of knowledge ought to be distinct from those involved in other epistemic appraisals. ${ }^{18}$ Clearly, expressivism about knowledge as stated here meets this requirement. We can see why the peculiar sort of evaluation involved in knowledge attribution is different from, say, the evaluation involved in saying that a belief is justified.

Expressivism about knowledge follows the contours of the forms of expressivism about ethics developed by Allan Gibbard and Simon Blackburn. It is important to note one point of difference, however. In the moral domain, two subjects A and B may accept different and incompatible sets of norms, and yet they may both count as accepting moral norms. A dispute between two such individuals may essentially concern which of two incompatible sets of norms to endorse, as distinct from the separate question whether some disputed issue fall under the norms. Hence, if A says that same-sex parenting is morally wrong there is a set of norms $\mathrm{N}_{\mathrm{A}}$, such that $\mathrm{A}$ in her remark expresses her commitment to $\mathrm{N}_{\mathrm{A}}$, and expresses her belief that same-sex parenting is prohibited by this set of norms. ${ }^{19} \mathrm{~B}$, who says that same-sex parenting is not wrong per se, thereby endorses a different set of norms $\mathrm{N}_{\mathrm{B}}$, and holds same-sex parenting to be licensed by those norms. Part of the disagreement between A and B is which set of norms to endorse.

When we turn to attributions of knowledge, the picture is slightly different. Suppose two subjects A and B disagree about whether a particular

needs a friendly amendment: holding S's epistemic condition with respect to $\mathrm{p}$ good enough by saying that $\mathrm{S}$ knows that $\mathrm{p}$ just is to endorse the k-norms for $\mathrm{p}$. 18 See Kvanvig, The Value of Knowledge and the Pursuit of Understanding, 183, where Kvanvig questions whether Greco's pragmatic version of epistemic attitudinalism can easily meet this requirement.

19 These sets of norms need not be complete, as Gibbard explains Allan Gibbard, Wise Choices, Apt Feelings : A Theory of Normative Judgement (Oxford: Clarendon, 1990). 
proposition should be designated as known by a particular subject, though neither rejects the proposition as false. ${ }^{20}$ Such disagreements do not normally constitute a disagreement about the proper content of the k-norms. This is for a good reason: one cannot accept a set of norms according to which one is permitted to doubt a belief, or to ignore it in one's practical deliberation, and yet still hold that endorsing this set of norms has anything to do with attributions of knowledge. So, attributions of knowledge are tied to the k-norms in way that the attribution of a right or just action is not tied to any specific set of moral norms. Yet, attributing knowledge essentially involves expressing an evaluation that takes the form of endorsing the k-norms.

I have used various expressions such as 'endorsing', 'expressing a proattitude', 'evaluating', 'expressing a commitment' and so on to designate the relation between an evaluator $\mathrm{A}$ and the k-norms obtaining when $\mathrm{A}$ attributes knowledge to some subject S. I take these expressions to be more or less equivalent, but I have made no attempt to define them. One may, of course, ask more in detail what it means to endorse a norm. For the purposes of this discussion, I trust that we do not need to answer this question, and perhaps there is no answer to be given. Citing Gibbard, we might have to say that endorsing a norm is expressing a psychological state that we are far from entirely understanding. We can hope not to define this state precisely, but to point to it'. ${ }^{21}$

There is a lot to be said about why we might want to consider expressivism about knowledge, or why we more generally might want to apply expressivism to the epistemic domain. Most obviously, the epistemic domain is normative in various ways, and features of the epistemic domain seem to exert

20 These are what one might call simple disagreements about knowledge. Of course, we often have complex disagreements, in which one disagrees not only about whether some proposition is known, but also whether it is true at all. 21 Gibbard, Wise Choices, Apt Feelings : A Theory of Normative Judgement, 55. 
a distinct type of motivational power. As is the case in the moral domain, it is not obvious how to account for these features, especially, of course, if one is inclined to metaphysical naturalism with respect to the epistemic domain. Simply positing separate epistemic facts does not really seem attractive; separate epistemic facts seem to be metaphysically strange entities, just as many have argued that separately existing moral facts would be. ${ }^{22}$ Reductionist accounts furthermore have problems of their own, problems that in many cases run parallel to those that have been explored in the ethical domain. The aim of this paper, though, is not to discuss these further issues.

\section{The Value of Knowing}

Turn now to the question of the value of knowledge. Expressivism about knowledge has fundamentally two things to offer in an explanation of the value of knowledge, or so I shall argue at any rate. First, treating a proposition in accordance with the k-norms is pragmatically beneficial, given the right sort of circumstances. This yields a kind of pragmatic explanation of why knowledge is valuable, or more valuable than, say, mere true belief. Second, saying that a belief is known is itself a distinct kind of positive valuation of that belief.

Consider first the suggestion that, in the right kind of cases, there is a kind of advantage to treating beliefs in accordance with the k-norms. Suppose I am about to leave for the airport in order to take a plane to important meeting. I tend to believe that my plan leaves at $2 \mathrm{pm}$, but not really trusting my memory, I do not consider myself as knowing this. If I am wrong, I might not catch the plane, and I will miss the meeting. This suggests that I have another look at my booking, just to make sure. Suppose then, that that after checking, I now begin to wonder whether there is a misprint on my ticket, or that I have confused the ticket with some other ticket. Again, this suggest that I embark on new inquires, perhaps I should take other measures to forestall the loss I incur by missing the

22 See the discussion in Cuneo about the parallels between expressivism in the epistemic and the ethical domain. 
meeting. Again it seems that I should take account of this remote possibility in my theoretical and practical deliberations. Clearly, however, error-possibilities may be too remote to merit attention, and correspondingly, beliefs may be secure enough to discount the possibility that they may be false. And clearly, I may benefit from treating my belief about the time of departure as beyond further inquiry, or as such that the possibility that the belief is false is discounted in my practical deliberations.

What this suggests, of course, is that we sometimes benefit by ignoring various possibilities that our beliefs are false. This is just the reason that applying the k-norms may benefit. Given a good enough epistemic position, treating a belief in accordance with the k-norms is valuable because this saves one from unnecessary inquiry, and because it reduces the cost of practical deliberation. ${ }^{23}$ Derivatively, being in an epistemic position such that one would be entitled to treat a true belief as known is being in a prudentially valuable position, even if one fails to benefit from this position because of a failure to regard the relevant belief as known. Let this be the pragmatic account of the value of knowledge.

This is not the place for a comparison of the merits of different accounts of the value of knowledge, but it is worth briefly noting how the pragmatic account differs from certain other accounts of the value of knowledge. The pragmatic account stresses the pragmatic effects of treating a belief in accordance with the k-norms. Though related in spirit, this differs from

23 Of course, the value of treating a belief as known may be outweighed by other factors, say the cost of bringing oneself in a sufficiently strong epistemic position. Moreover, even when other things are equal, there may be special circumstances cancelling the value derived from treating a belief as known. Consider a world in which an evil demon dislikes subjects that appear certain about their worldly beliefs and therefore severely punishes those that regard those beliefs as known but not those who merely regard their beliefs as more or less justified. 
instrumentalist accounts holding that knowledge is valuable (or more valuable than mere true belief) in virtue of being instrumentally valuable (more instrumentally valuable than mere true belief) in certain ways. Alvin Goldman and Erik Olsson has recently proposed two versions of instrumentalism, one of which claims that 'the probability of having more true belief (of a similar kind) in the future is greater conditional on S's knowing that $\mathrm{p}$ than condition on S's merely truly believing that p. ${ }^{24}$ The reason this is so depends on reliabilism, and the assumption that reliable belief forming processes are usually stable and usually applies to more than one problem. So, if one knows that $\mathrm{p}$ at some time, then one does so in virtue of a reliable belief forming process, which is likely to be stable and applicable in similar circumstances in the future. So, knowing that $\mathrm{p}$ at $\mathrm{t}$ is instrumentally related to acquiring true propositions in the future.

A distinct but similar idea is that known beliefs are more stable than mere true beliefs, and this accounts for the greater value of knowledge. Williamson is the best known recent proponent of this view, the core of which he states as follows: 'If your cognitive faculties are in good order, the probability of your believing $p$ tomorrow is greater conditional on your knowing $p$ today than on your merely believing $p$ truly today (that is, believing $p$ truly without knowing $p$ ). Consequently, the probability of your believing $p$ tomorrow is greater conditional on your knowing $p$ today that on your believing $p$ truly today. ${ }^{25}$

While both instrumentalism and the stability view may be right in their claims about how knowledge relates to certain other benefits, the pragmatic account focus on a different set of claims. According to the pragmatic account, treating a belief as a known belief is beneficial in the right sort of circumstances, even when this is not related to preserving one's belief in the future, or the acquisition of other true beliefs in the future. I do believe that the

24 Goldman and Olsson, "Reliabilism and the Value of Knowledge," 28.

25 Williamson, Knowledge and Its Limits, 79. 
pragmatic account is more plausible than both instrumentalism and the stability view, but space does not permit further discussion.

Expressivism about knowledge does not directly entail the pragmatic account, of course, and no doubt other views could endorse the pragmatic account of the value of knowledge. Indeed, as expressivism about knowledge only offers a theory of the content of locutions such as 'Adrian knows that p', expressivism about knowledge is not even committed to an expressivist rendering the distinct kind of sentences that could be used to attribute value to knowledge state, e.g. sentences such as 'knowledge is more valuable than mere true belief'.

Nonetheless, I suggest that expressivism about knowledge and the pragmatic account of the value of knowledge go well together. Clearly, the norms featuring in the pragmatic account are natural phenomena, and we need an explanation of their nature, how they arise, how they are sustained, transmitted, and how they interact with our cognitive and practical life. Expressivism about knowledge yield just such an account, though I have of course made no attempt to show this account to be superior to other naturalistic accounts.

Turn now to the second suggestion, that attributions of knowledge are themselves attributions of distinct kinds of positive value. This requires some explanation. First, the relevant claims in expressivism about knowledge are that attributions of knowledge involve endorsing k-norms regarding particular beliefs, and that endorsing k-norms is itself a way of expressing a distinct type of pro-attitude. This is why attributions of knowledge can be viewed as expressions of certain distinct positive evaluations.

Second, consider the claim that endorsing k-norms involves a positive evaluation. This claim in turn requires further explanation. Epistemic expressivism holds that attributing knowledge involves endorsing a set of norms. However, endorsing a set of norms regarding some item doesn't by itself imply that this item is thereby valued positively. For example, thinking that someone ought to be punished for a terrible crime is not to express a 
positive evaluation of this person or his actions. So, provided that attributing knowledge involves endorsing the k-norms, why does attributing knowledge amount to a positive valuation?

The answer, I suggest, is that this is because endorsing the k-norms concerns a prudentially valuable option, as noted above, whether or not the subject in question benefits from it. This means, in more detail, that when A takes $\mathrm{S}$ to be in a sufficiently good epistemic position, then A's applying the knorms to S's belief that $\mathrm{p}$ commits $\mathrm{A}$ to thinking that $\mathrm{S}$ is better off observing the k-norms. Due to these considerations it is reasonable to view endorsing the k-norms as an expression of a positive evaluation rather than a negative or neutral evaluation.

\section{Swamping and the Way to Larissa}

Consider now how all this applies The Meno Problem. This is the problem of explaining why knowledge is more valuable than mere true belief. Why is knowing the way to Larissa somehow better or to be preferred compared to having a true belief regarding the same, considering that both will take one there, should one decide to go? To make the question a bit more precise what is being compared, we may make use of the terminology introduced earlier and consider the following case (Case A):

Adrian is in a strong epistemic position $\mathrm{E}_{\mathrm{s}}$ with respect to his belief that $\mathrm{p}$, and Adrian regards himself as knowing that $\mathrm{p}$ is the case. Astor also believes that $p$ is true, though he is in a weaker epistemic position $E_{w}$ with respect to p. Accordingly, Astor regards himself as somewhat justified in his belief that $\mathrm{p}$, though he does not regard himself as knowing that $p$. Suppose finally that the truth of $p$ has equal practical importance for Adrian and Astor.

The question is why Adrian's epistemic situation (where I take his epistemic situation to consist of his epistemic position with respect to $p$, the truth of the 
belief that $\mathrm{p}$, and the fact that he regards himself as knowing that $\mathrm{p}$ ) more valuable than the epistemic situation of Astor? Both of them believe that $p$, they have at least some justification for that belief, their belief is true, and the practical import of the belief is the same for both of them?

It is worth noting how Case A differs from common ways of stating the Meno Problem. Often, in discussions of the Meno Problem, the question is taken to be how knowledge can be more valuable than mere true belief. This way of stating the question is unfortunate if it is not specified what a mere true belief is. Do we compare knowledge to an accidentially true belief or to a belief held with some justification though not enough for the belief to qualify as knowledge? Also, Case A specifies whether the subjects involved take themselves to be knowing proposition in question or not. The reason why this matters is that intuitively, S's knowing that $\mathrm{p}$ may have no particular value, or less value, when $\mathrm{S}$ does not consider herself as knowing that $\mathrm{p}$.

To avoid these kinds of problems, Case A specifies that Adrian's belief that $\mathrm{p}$ is held in a strong epistemic position, whereas Astor's belief is held in a somewhat weaker position. And it is specified that Adrian takes himself to know that $\mathrm{p}$, while Astor does not.

As we have seen, expressivism about knowledge supports the following answer. Adrian's situation is better than Astor's because Adrian is relieved of the cost of further inquiries, and does not need to accommodate the possibility that his belief that $\mathrm{p}$ might be wrong in her practical deliberations. Astor, by contrast, is not relieved of these additional costs. In addition, Adrian's considering himself as knowing is a way for Adrian to express a distinct positive evaluation of his own epistemic position. And given that we, as evaluators of Adrian's and Astor's situations, also take Adrian to know that $\mathrm{p}$, we similarly apportion a kind of epistemic appraisal on Adrian that is not due to Astor.

Clearly, given the way Case A is constructed, we can see an obvious method for constructing new cases to which a theory of the value of knowledge should provide plausible answers. To start with, the two parameters to vary are 
strength of epistemic position (this parameter may take the value of strong and weak) and epistemic self-assessment (subjects may take themselves to know a particular proposition or take themselves to be merely somewhat justified in believing it). Other parameters to include might involve Gettier-complications. A full account of the value of knowledge would explain if or why a known belief is more valuable than a true justified belief that would be knowledge, were it not for the occurrence of a Gettier-style incident.

Analysing how an expressivist account of the value of knowledge deals with a range of these cases in comparison with competing accounts of the value of knowledge is the topic of at least another paper. Suffice it here to note that the expressivist account will emphasise the pragmatic effects of regarding oneself as knowing a proposition, and the sort of positive evaluation expressed when saying that someone knows. ${ }^{26}$ Some implications of this are worth noting. Suppose that Belinda is in a strong epistemic position with respect to the true proposition that $\mathrm{p}$, yet she fails to consider herself as knowing that $\mathrm{p}$. Belinda's situation then comes out as less valuable than that of Bertrand, who is in the same strong position as Belinda's but in addition does consider himself as knowing. Or consider Carl who is in a weak epistemic position with regard to some true proposition $\mathrm{p}$, and yet regards himself as knowing that $\mathrm{p}$. Clearly, there seems to be a sense in which Carl is better positioned than Calvin, who is in the same weak epistemic position with regards to $p$, but who does not consider himself as knowing that p. I such cases we might ask: when one's epistemic position is fairly weak but the target belief nonetheless true, why is it better to be regard oneself to be in a fairly weak epistemic position with respect to that true proposition than taking oneself to know it? I suggest that the account on offer should reply that Carl is in a sense lucky. Although his epistemic position is not good enough to warrant it, he regards himself as knowing that $\mathrm{p}$, and due to luck he benefits from this. In a sense mistaking mere

26 Note though, that nothing in the account on offer rules out that in many cases known beliefs are valuable for instrumental reasons or stability reasons. 
justified belief or even unjustified belief for knowledge may benefit you - if you are lucky. ${ }^{27}$

Yet another point worth noting concerns the modalities of the value of knowledge. Many commentators assume that the value of knowledge is a distinct kind of value - epistemic value - which is held to be different in nature and extension from prudential value. Often discussion of the value of knowledge proceed on some assumption of value monism, according to which only simpler states such as true belief has basic epistemic value. On this assumption, part of the problem is to explain how knowledge can have added value over that of true belief. In many passages Kvanvig operates with the additional assumption that the value of knowledge must be explainable in terms of the constituents of knowledge, or the similar assumption that the value of knowledge should be explainable by our preferred theory of knowledge. Clearly, these and similar further assumptions underlying various puzzles regarding the putative value of knowledge are quite contentious, and none of them seem universally shared among those working on the value problem.

Clearly, the account of the value of knowledge based on expressivism about knowledge fails to respect a range of the further assumptions about the value of knowledge. For example, the expressivist account does not imply that knowledge is valuable in virtue of the constituents of knowledge. Though I cannot argue the point more here, I think it is unlikely that this could be turned into a strong objection against the expressivist account, and the reason is that these further constraints are themselves insufficiently motivated.

Turn now briefly to the swamping problem. ${ }^{28}$ Suppose for a moment that what matters for knowledge is reliably produced true belief. Suppose,

27 See the fuller discussion of these cases in my 'Getting the Meno Problem Right' (forthcoming).

28 For discussions of this problem, see Kvanvig, The Value of Knowledge and the Pursuit of Understanding. and L. Zagzebski, "The Search for the Source of Epistemic Good," Metaphilosophy 34, no. 1-2 (2003). 
moreover, that some form of value monism is true. This is the assumption that true belief is the only thing of basic epistemic interest, or the only basic epistemic value. Whatever epistemic value accrues to knowledge or any other epistemic state must be accounted for in terms of the value of true belief. The question then becomes how, given these assumptions, can knowledge be more valuable than mere true belief? This question is thought to be especially hard for the reliabilist. For the reliabilist, the difference between a mere true belief and knowledge lies in the reliable processes that produce knowledge. But if a belief is true and therefore valuable, how can the fact that it was reliably produced make it even more valuable? How can one explain this latter increment in value, given one's commitment to value monism?

As we have seen, expressivism about knowledge can sustain the view that, given the right kind of circumstances, complying with the k-norms is valuable. And attributions of knowledge are themselves ways of bestowing value. Of course, expressivism about knowledge is not intimately related to reliabilism. If reliabilism is taken to provide an analysis of the meaning for the word 'knowledge' and its cognates, then reliabilism and expressivism about knowledge are at odds with each other. Similarly, if reliabilism is supposed to provide a reductive account of knowledge considered as a distinct type of epistemic state, the expressivist about knowledge might deny reliabilism. Nonetheless, I take the basic idea in expressivism about knowledge to be compatible with the reliabilist insistence that what matters for knowledge apart from true belief is reliable belief formation. The most important epistemically relevant facts for our attribution of knowledge concern the reliability of the relevant belief forming processes. So, expressivism about knowledge can motivate why we should value reliably produced true belief in a certain way that we do not value mere true belief.

Of course, one might suspect that this reply to the swamping problem simply denies one of the basic assumptions in the swamping problem, namely value monism according to which the only thing of basic epistemic interest or basic epistemic value is true belief. This, of course, is in a sense right. But it is 
important to note the following: epistemic value monism derives much of its plausibility from the fact that, in our inquiry, the aim of inquiry should be true belief, and nothing but true belief. And as we shall see below, the expressivist about knowledge fully accepts this. So, while expressivism about knowledge denies value monism, it preserves the guiding intuition behind value monism.

\section{Inquiry, final value, distinct value and epistemic value}

\section{(a) The role of knowledge in inquiry}

What is the role of knowledge in inquiry? And how does the value of knowledge figure in inquiry, if at all? Several years ago Mark Kaplan argued that knowledge cannot have the importance it is often assumed to have in epistemology. Kaplan wrote:

Imagine that you have been engaging in inquiry. Being a responsible inquirer, you have carefully weighed evidence and argument and have come to the conclusion that the weight of evidence clearly favours $P$ and, so, you have concluded that $P$ is true. Suppose you now ask yourself, "But do I know that $P$ ?" Notice that on the justified-true-belief analysis of knowledge, there is nothing to find out, nothing to do. Having already satisfied yourself that $P$ is true and that the evidence supports your contention that $P$ is true, you have ipso facto already satisfied yourself that you have justified true belief. From where you sit, determining whether you believe $P$ with justification and determine whether you know that $P$ come to the same thing. But then, far from being integral to your pursuit of inquiry, distinguishing the propositions you know from those you don't know is, in the justified-true-belief analysis, a fifth wheel. 'Knowledge' turns out to be nothing more than a 
honorific you may bestow on those of your beliefs which you consider justified should using the term 'justified' alone seem tiresome. ${ }^{29}$

One main point that Kaplan makes is that, as far as inquiry is concerned, knowledge is simply not relevant. What matters for one's inquiry is being justified in the beliefs one accepts - any further question about knowledge is idle for one's inquiry. Though it might seem surprising in a paper on the value of knowledge, I believe that Kaplan is right about this. There is a very natural sense in which one's prime concern in inquiry should be the target propositions of one's inquiry and one's putative reasons for accepting as true those propositions. One's prime concern should not be whether one's beliefs in any of those propositions qualify as knowledge.

Now, Kaplan's point would pose a threat to many accounts of the value of knowledge, as they may have to concede that while knowledge is valuable in certain epistemic senses, knowledge is nonetheless not important in inquiry. Just as knowledge, according to Kaplan, threatens to be a fifth wheel, the value of knowledge could turn out to be completely idle as far as our inquiries are concerned. Such an implication of a theory of the value of knowledge would be highly undesirable, I believe.

One attractive feature of the account of the value of knowledge that I offer is that it can acknowledge Kaplan's point, and yet explain the crucial role that attributions of knowledge have in inquiry. Saying that a belief is known rather than merely believed with some justification is to insist that further inquiry is pointless and that the possibility that $\mathrm{p}$ is false should be discounted in practical deliberation. ${ }^{30}$ This, in turn, is to adopt a distinctive pro-attitude to of Philosophy 82, no. 7 (1985): 355.

30 Note the similar remarks that Kvanvig makes about the aims of inquiry, in his Kvanvig, The Value of Knowledge and the Pursuit of Understanding, $143 \mathrm{ff}$. 
one's belief, and the evidence one has for this belief. It is not, the expressivist about knowledge claims, a matter of asserting a further fact, access to which one may have due to a separate line of inquiry into the epistemic status of the belief.

Here is a way to state the point. Suppose that I am interested in the question whether $\mathrm{p}$, and thus inquire into the truth of $\mathrm{p}$. Let us say that I engage in inquiry whether $\mathrm{p}$. I conduct my inquiry whether $\mathrm{p}$ by assessing the evidence for or against $\mathrm{p}$, by looking for more evidence for or against $\mathrm{p}$, and so on. It seems that the guiding aim of inquiry whether $p$ is to believe the truth of $p$ (if $p$ is true), and to believe the falsity of $p$ (if $p$ is false). Thus, the aim of inquiry whether $\mathrm{p}$ is not to decide the truth of the proposition expressed by 'I know that p'. Thus, the question 'But do I know that p?' is a further question relative to my inquiry whether $\mathrm{p}$. And since I conduct my inquiry whether $\mathrm{p}$ by assessing evidence for and against $\mathrm{p}$, the further question 'But do I know that $\mathrm{p}$ ? seems irrelevant to my inquiry whether $\mathrm{p}$. Even if, as a corollary to my inquiry whether $\mathrm{p}$ I were interested in knowing the answer to the further question 'But do I know that p', then there would no separate line of inquiry that I could pursue to determine the truth of this proposition. In general, all I could do would be to reassess my evidence for $\mathrm{p}$. So, it seems that knowledge that $\mathrm{p}$ plays no separate role in my inquiry whether p. However, this is misleading, since attributions of knowledge that $\mathrm{p}$ have an important role in inquiry whether p. Roughly, in inquiry whether $p$, saying that the belief that $\mathrm{p}$ is known serves to express the attitude that further inquiry is pointless, and that the possibility that $\mathrm{p}$ is false should be discounted in practical deliberation. Or as one might put it: If true belief that $p$ (not-p) is the aim of inquiry whether $p$, then regarding one's belief that $\mathrm{p}$ (not-p) as known is the end of inquiry whether $\mathrm{p}$. It is where inquiry should stop.

Note one more point. This account of the role of knowledge or attributions of knowledge in inquiry may also partially explain why the value problem of knowledge is generated in the first place. The value problem may arise from two conflicting intuitions. The first holds that what matters in inquiry 
as well as for practical purposed is true belief, and whatever reasons we have for regarding a belief as true. The other conflicting intuition has it that it is somehow better to have known beliefs as distinct from, say, mere true belief. If one is in a position to designate one's own beliefs a known, one is for that reason better positioned. The account of the value of knowledge accords both intuitions their due place, and explains why they are not in conflict.

\section{(b) Final value}

Many commentators think that knowledge has final value. An item has final value just when it is valuable for its own sake. This is distinct from items that are valuable for the sake of something else, say by being instrumentally valuable. Final value is also to be distinguished from intrinsic value. Some item is intrinsically valuable just if it is valuable in virtue of its intrinsic properties. It is important to notice that an item may be finally valuable without being intrinsically valuable. This happens when the item is valuable for its own sake, but not valuable merely in virtue of its intrinsic properties. On preference theories of value, for example, we may have a preference that some item exist for its own sake, and yet the value does not reside merely in intrinsic properties, but also in certain relational properties, namely the item being the object of a suitable preference.

It is not obvious, of course, that knowledge really is finally valuable. It is not even obvious that we have a considered intuition to the effect that knowledge is finally valuable. Hence, it is unclear if successful theories of the value of knowledge need imply that knowledge is finally valuable.

Nonetheless, it might be worth pointing out that expressivism about knowledge supports the idea that knowledge is, in a sense, valuable for its own sake, and therefore finally valuable. Here is how it goes. Suppose that I am interested in the question whether $\mathrm{p}$. I thus inquire into the truth of $\mathrm{p}$ by assessing the evidence for $\mathrm{p}$, by looking for more evidence for $\mathrm{p}$, and so on. The object of this inquiry, we may say, is to believe the truth of $p$ (if $p$ is true), and to believe the falsity of $p$ (if $p$ is false). Given my inquiry whether $p$, knowing 
that $\mathrm{p}$ (or knowing that not-p) is valuable for its own sake in just the sense that knowing that $\mathrm{p}$ is valuable, though not instrumentally valuable relative to some other goal which forms part of the inquiry whether p. As explained above, in the inquiry whether $\mathrm{p}$, to know that $\mathrm{p}$ features as an end of this inquiry, as a kind of valuable end point that does not serve to realise some other goal that is part of the inquiry. It is not, for example, that we want to know that $p$ because this is instrumental to the aim of believing $\mathrm{p}$ just if $\mathrm{p}$ is true. Contrast this with canvassing some bit of evidence that I hope will make me able to decide between $\mathrm{p}$ and non-p. Given the project of inquiry whether $\mathrm{p}$, finding this bit of evidence is instrumentally valuable - it is valuable in the light of a particular further goal, that of believing the truth about $\mathrm{p}$. Knowing whether $\mathrm{p}$ is not in this sense valuable in virtue of being instrumental to some further goal.

One might object that since knowing that $\mathrm{p}$ is suggested to be finally valuable given the inquiry whether $\mathrm{p}$, this really amounts to saying that knowledge that $\mathrm{p}$ is not finally valuable after all. But this would be a mistake. What the objection really says is that knowledge that $\mathrm{p}$ is not intrinsically valuable. The objection points out that the value of knowledge that $p$ depends on certain relational features, principal among them that one undertakes the inquiry whether $\mathrm{p}$. But the claim proposed was only that knowledge is finally valuable, not that it is intrinsically valuable.

\section{(c) Knowledge has its own distinct kind of value}

Another point worth noting is that expressivism about knowledge explains why the value of knowledge is special as compared to the value of mere true belief or mere true justified belief. This addresses what Duncan Pritchard calls the tertiary value problem, the problem of explaining 'why knowledge has not just greater degree but also different kind of value than whatever falls short of knowledge. ${ }^{31}$

31 Duncan Pritchard, Alan Millar, and Adrian Haddock, The Nature and Value of Knowledge: Three Investigations (Oxford University Press, 2009), 13 
It is not entirely obvious, of course, that there is a pre-theoretical reason to think that there is a tertiary value problem, but for the sake of discussion assume that this is so. Consider for example the view that knowledge is valuable in virtue of the value of justified belief. This view implies that the kind of value that pertains to known belief is just the same as the kind that arises from justified belief, except that knowledge may generally contain more of it than mere justified true belief. The reason such a view may be held to be problematic is that we do seem to treat known beliefs quite differently from mere justified true belief. And there might even be some justified beliefs whose degree of justification is greater than some known beliefs, and yet we treat the known beliefs in a special way. This is what the tertiary value problem seeks to bring out.

Expressivism about knowledge can easily reply to the tertiary value problem. The value of knowledge is special simply because arises from endorsing the k-norms rather than some other set of norms; so, the value of knowledge is different in nature of whatever value we bestow on justified belief or true belief, and the value of knowledge is not a function of these other kinds of value. This is what gives the value of knowledge its distinct nature.

\section{(d) Is this an account of epistemic value?}

One might reasonably wonder whether the account on offer really explains the distinctive epistemic value of knowledge, or whether it rather attributes only some form of practical value to knowledge. And if the latter, one might worry if this is a problem. Shouldn't an account of the value of knowledge explain why knowledge has a higher epistemic value than true belief, or mere true belief?

This is a difficult question, in part because it is not always clear what it is for some value to be epistemic rather than, say, practical. In any case, many contributors assume that the relevant kind of value that knowledge might have is epistemic value. Epistemic value is the kind of value that pertains to epistemic processes, states and properties, such as justified belief, true belief, or 
processes of proper reasoning. One should, as an epistemic agent - an inquiring mind - prefer knowledge to true belief, other things being equal, not because knowledge may have greater practical value, though this may sometimes also be true, but because of the greater epistemic value of knowledge. Or so the assumption is, at least. So, epistemic value is thought to be a distinct kind of value that differ in nature and extension from prudential, moral, and aesthetic value.

Suppose we lay down as a requirement that successful theories of the value of knowledge explain the value of knowledge in terms of epistemic value, rather than some other kind of value. The account of the value of knowledge based on expressivism about knowledge could accommodate this requirement, I think. To see this, consider the two most obvious ways in which one might be able to individuate types of value. One way would be to individuate type of value in terms of the types of object being valued. Suppose we assume that true belief is an epistemic type object. Expressivism about the value of knowledge would have no problem with this assumption. In so far as the value of knowledge arise from the distinctive patterns of valuations that we bestow on true beliefs when held under appropriate circumstances, this value would be epistemic in kind, merely in virtue of concerning an epistemic type of object.

The basic assumption about how to type individuate value seems plausible in certain case, at least. Suppose that have been working on a painting for some time now, and that I now at last consider the painting complete. We can think of this as the adoption of a distinctive evaluative attitude to the painting, and attitude which include that I think of the painting has having reached its final aesthetic form in terms of colours, texture, shape and so on. By adopting this attitude, I urge myself to stop worrying about other ways I could have expressed my ideas, or other shades or nuances I could add to the painting, and I express my readiness for considering the painting for exhibition or for sale. Suppose we say that by considering the painting as complete, I adopt a distinctive evaluative attitude to the painting, and suppose that this bestows value on the painting. It seems, of course, that the evaluative attitude 
and the value generated is aesthetic in kind. What makes it so, we can ask? One answer seems quite tempting: the valuational stance I adopt to the painting is aesthetic in kind in virtue of the kind of object is has. The painting is an aethetic object. Had I adopted an evaluative stance with the same structure to a very different kind of object, the resulting value might have been different in type.

Despite this, type individuation of valuational stances in terms the type of their objects may not be plausible in all cases. After all, one can desire that a belief be true for aesthetic reasons, or prefer to own one painting rather than another for monetary reasons, which are distinct from aesthetic reasons. So, surely, one can value aesthetic objects without turning one's valuing into an aesthetic kind of valuing.

So, maybe a more plausible view is functionalist in nature, holding that what makes something an evaluative attitude of an epistemic kind is a matter of the role it plays in our intellectual ecology, as it were. ${ }^{32}$ Similarly, what makes some value epistemic rather than aesthetic is a question of how our general attitudes to this value relates to epistemic endeavours. This type of view about type individuation may be more plausible. But again, assuming that this is the correct way to individuate types of value, we surely get that expressivism about the value of knowledge accrues epistemic value to knowledge. The evaluational attitude that is central to expressivism about the value of knowledge is epistemic in character in virtue of relating firmly to epistemic notions such as evidence and inquiry.

\section{(e) Why knowledge is also of greater practical value}

One final remark on the practical value of knowledge. Whatever one thinks about epistemic value of knowledge there is a parallel problem concerning the practical value of knowledge. Under one interpretation, this is part of what the Meno Problem brings out. The Meno Problem arises from realising that

32 Kaplan's expression, see Mark Kaplan, "Critical Study: Who Cares What You Know?," The Philosophical Quarterly 53, no. 210 (2003): 106. 
knowing the way to Larissa appears to be of no greater practical use than having a mere true belief to the same effect. Both epistemic states will bring one equally safely and expediently to Larissa, should one decide to go. Yet, there is nonetheless a sense that knowing the way to Larissa seems somehow practically better than merely having a true belief regarding this matter (or so one might argue, at least). On reflection, however, it is not obvious why this is so. After all, what seems to matter from a practical point of view is true belief, and all mere true belief and mere true justified belief feature that just as well as knowledge.

If this is right, it is not as if we have to make a choice between accounting for the greater epistemic value of knowledge on the one hand, and the greater practical value, on the other. Rather, it seems plausible that the value problem for knowledge concerns two dimensions of value, epistemic value and practical value. Both pose parallel but distinct challenges.

\section{Concluding Remarks}

The aim of this paper has not been to defend epistemic expressivism, or even endorse this view. At this early stage in the discussion, I have only sought to develop how this kind of view may account for the value of knowledge. Further important questions concerns whether an account of the value of knowledge based on expressivism about knowledge is better or at least as good as other accounts of the value or knowledge. And, of course, a crucial question is whether expressivism about knowledge is a sufficiently motivated view. ${ }^{33}$

33 Earlier versions of material in this paper were presented at Danish Epistemology Network workshops in 2006, at the Amsterdam Conference on the Value of Knowledge, August 2007, The European Epistemology Network Meeting in Geneva, September 2007, and at the Analytic Philosophy Workshop, Amsterdam, January 2008. The most direct ancestor to this paper were presented at the Bled Epistemology Conference in 2009. I would like to thank all the audiences for stimulating discussions and important suggestions, 
in particular Martijn Blauw, Matthew Chrisman, Mikkel Gerken, Sanford Goldberg, David Henderson, Jesper Kallestrup, Jennifer Lackey, Adam Morton, Erik Olsson, Christian Piller, Duncan Pritchard, and Michael Ridge. Thanks to an anonymous referee for Acta Analytica who made some very helpful suggestions. 


\section{References}

Blackburn, Simon. "Securing the Nots: Moral Epistemology for the QuasiRealist." In Moral Knowledge. New Readings in Moral Epistemology, edited by Walter Sinnott-Armstrong and Mark Timmons: Oxford University Press, 1996.

Chrisman, Matthew. "From Epistemic Contextualism to Epistemic Expressivism." Philosophical Studies 135, (2007): 225-54.

—. "From Epistemic Expressivism to Epistemic Inferentialism." In Social Epistemology, edited by Adrian Haddock, Duncan Pritchard and Alan Millar: Oxford University Press, 2009 (forthcoming).

Cuneo, Terence. The Normative Web : An Argument for Moral Realism. Oxford: Oxford University Press, 2007.

Field, H. "Epistemological Nonfactualism and the a Prioricity of Logic." Philosophical Studies 92, no. 1-2 (1998): 1-24.

—_. "Epistemology without Metaphysics." Philosophical Studies 143, (2009): 249-90.

Gibbard, Allan. Thinking How to Live. Cambridge, Mass. ; London: Harvard University Press, 2003.

- Wise Choices, Apt Feelings : A Theory of Normative Judgement. Oxford: Clarendon, 1990.

Goldman, Alvin I., and E. J Olsson. "Reliabilism and the Value of Knowledge." In Epistemic Value, edited by Duncan Pritchard: Oxford University Press, 2009.

Heller, M. "The Proper Role for Contextualism in an Anti-Luck Epistemology." Nous (1999): 115-29.

Kaplan, Mark. "Critical Study: Who Cares What You Know?" The Philosophical Quarterly 53, no. 210 (2003): 105-16.

- "It's Not What You Know That Counts." The Journal of Philosophy 82, no. 7 (1985): 350-63.

Kvanvig, Jonathan L. The Value of Knowledge and the Pursuit of Understanding, Cambridge Studies in Philosophy. Cambridge, UK ; New York: Cambridge University Press, 2003. 
Lynch, Michael. "Truth, Value and Epistemic Expressivism." Philosophy and Phenomenological Research LXXIX, no. No 1 (2009): 76-97.

Pritchard, Duncan, Alan Millar, and Adrian Haddock. The Nature and Value of Knowledge:

Three Investigations: Oxford University Press, 2009.

Williamson, Timothy. Knowledge and Its Limits. Oxford ; New York: Oxford University Press, 2000.

Zagzebski, L. "The Search for the Source of Epistemic Good." Metaphilosophy 34, no. 1-2 (2003): 12-28. 